\title{
Novel, panzootic and hybrid genotypes of amphibian chytridiomycosis associated with the bullfrog trade
}

\author{
LISA M. SCHLOEGEL,$*$ LUÍS FELIPE TOLEDO,† JOYCE E. LONGCORE, \\ SASHA E. GREENSPAN, $\ddagger$ CONRADO AUGUSTO VIEIRA,† MARIA LEE,§SERENA ZHAO,§ \\ CATHERINE WANGEN,§ CLAUDIA MARIS FERREIRA, \ MÁRCIO HIPOLITO,** \\ ANGELA J. DAVIES, †+ CHRISTINA A. CUOMO, 㧊 PETER DASZAK* and TIMOTHY Y. JAMES§ \\ *EcoHealth Alliance, New York, NY 10001, USA, +Museu de Zoologia, "Prof. Adão José Cardoso", Instituto de Biologia (IB) \\ Universidade Estadual de Campinas (UNICAMP), Campinas, SP, Brazil, $\ddagger$ School of Biology and Ecology, University of Maine, \\ Orono, ME 04469, USA, §Department of Ecology and Evolutionary Biology, University of Michigan, Ann Arbor, MI 48109, USA, \\ -Fishery Institute, São Paulo, Brazil, **Biological Institute, São Paulo, Brazil, +十School of Life Sciences, Kingston University, \\ Kingston-upon-Thames, Surrey KT1 2EE, UK, 抽he Broad Institute of MIT and Harvard, Cambridge, MA 02142, USA
}

\begin{abstract}
Global amphibian declines are linked with the presence of specific, highly virulent genotypes of the emerging fungal disease chytridiomycosis caused by Batrachochytrium dendrobatidis $(B d)$ known as the global panzootic lineage ( $B d-G P L)$. The global trade in amphibians for human consumption is suspected to have facilitated emergence of the disease, but evidence to support this is largely lacking. Here, we investigated the role the Lithobates catesbeianus (North American bullfrog) trade in spreading $B d$ genotypes by comparing strains associated with $L$. catesbeianus to a global panel using 36 sequenced loci from multiple chromosomal regions. Most bullfrogs were infected with $B d-G P L$ genotypes, but we also detected novel, highly divergent $B d$ genotypes ( $B d$-Brazil) from a live bullfrog in a US market and from native Brazilian anurans in the Atlantic Forest where bullfrogs are widely farmed. Sexual reproduction was also detected for the first time in $B d$ in the form of a hybrid genotype between the $B d$-GPL and $B d$-Brazil lineages in the Atlantic Forest. Despite the demonstration that ribosomal RNA types in $B d$ fail to undergo concerted evolution (over 20 sequence types may be found in a single strain), the $B d$-GPL and $B d$-Brazil lineages form largely separate clusters of related internal transcribed spacer (ITS) RNA sequences. Using ITS sequences, we then demonstrate the presence of $B d$-Brazil in Japan, primarily on invasive L. catesbeianus. The finding that $B d$ is capable of sexual reproduction between panzootic and endemic genotypes emphasizes the risk of international wildlife trade as a source of additional $B d$ epizootics owing to hybridization.
\end{abstract}

Keywords: aneuploidy, chytrid, emerging infectious disease, loss of heterozygosity, ranaculture

Received 12 February 2012; revision received 8 June 2012; accepted 14 June 2012

\section{Introduction}

Emerging infectious diseases (EIDs) of wildlife threaten biodiversity and ecosystem health (Schloegel et al. 2006; Fisher et al. 2012). Among the factors that lead to infectious disease emergence are as follows: evolution of

Correspondence: Lisa M. Schloegel and Timothy Y. James, Fax: 1-212-380-4465 and 1-734-763-0544; E-mail: schloegel@ecohealthalliance.org and tyjames@umich.edu novel genotypes by mutation or recombination, translocation of pathogens onto naïve hosts and changes in environment (Walker et al. 1996; Morens et al. 2004). Particularly relevant to a 'globalized' planet is the consistent threat of anthropogenic introduction of pathogens into naïve host populations of wildlife (pathogen pollution) through long-distance vectoring of disease (Daszak et al. 2000; Warnecke et al. 2012). These introductions are facilitated by the global trade in wildlife, 
which is in the tens of billions of animals per year and is largely without regulatory disease surveillance (Smith et al. 2009). Detailed risk analyses of pathogen transport on wildlife, supported by scientific investigations into the geographic distribution and spread of pathogen genotypes, are needed to predict source populations of future outbreaks and to suggest ways of reducing pathogen emergence and spread (Archie et al. 2008).

Chytridiomycosis is a wildlife EID caused by Batrachochytrium dendrobatidis $(B d)$, a fungus that is associated with the global decline, and sometimes extinctions, of amphibians (Schloegel et al. 2006; Skerratt et al. 2007; Crawford et al. 2010). Several hypotheses attempt to explain the recent emergence of chytridiomycosis, including global movement of amphibians and climate change (Rachowicz et al. 2005; Pounds et al. 2006; Fisher et al. 2009). $B d$ has a broad host range, but many species, such as the North American bullfrog Lithobates catesbeianus, are highly resistant yet often infected and may act as disease vectors (Garner et al. 2006; Schloegel et al. 2009, 2010b). Lithobates catesbeianus must also be scrutinized with regard to international spread of $B d$, because it has been established throughout South America and Asia for the purposes of the global trade in frog legs (Flores Nava 2005) and has established invasive populations in western North America, South America, Europe and Asia (Lever 2003).

Comparisons of $B d$ strains from multiple continents and hosts by multi-locus sequence typing (MLST) have yielded little evidence of geographic or host structuring and instead suggest recent intercontinental spread (Morehouse et al. 2003; Morgan et al. 2007; James et al. 2009). The data implicate an extreme genetic bottleneck before the panzootic spread, because the allelic variation observed in a single strain isolated from $L$. catesbeianus was as great as the known diversity from a global sample of strains (James et al. 2009). The rapid and recent geographic expansion of $B d$ temporally correlates with globally declining amphibian populations but limits investigations into the genetic and geographic origins of the panzootic. Recently, however, Farrer et al. (2011) reported genotypes of $B d$ that are genetically divergent and less virulent relative to the genotypes associated with most declining amphibian populations globally [the global panzootic lineage ( $B d$-GPL) genotypes]. Consistent with the heightened virulence properties reported in $B d$-GPL strains, the inference is that the $B d-$ GPL is a recent genotype that is replacing endemic genotypes, which have had longer associations with their hosts (Farrer et al. 2011).

Although molecular variation among strains is thus far insufficient to infer the origin and spread of chytridiomycosis, the data suggest that global movement of amphibians contributes to $B d$ gene pools (Walker et al. 2008;
Goka et al. 2009; Schloegel et al. 2010b). A study of Bd diversity in Japan by Goka et al. (2009), who analysed partial rRNA internal transcribed spacer (ITS) region sequences from DNA from swabbed amphibians, suggested extensive haplotype diversity, particularly associated with invasive L. catesbeianus. These data also provided the first indication that endemic genotypes of $B d$ may exist because one well-supported branch of the phylogeny was restricted to sequences obtained from $B d$ on Andrias japonicus (giant Japanese salamander). Based on these endemic genotypes and the absence of diseaseassociated amphibian declines in Japan, the authors speculated that $B d$ may have originated in Asia. Later, additional evidence for endemic genotypes was suggested by novel genotypes discovered by Farrer et al. (2011) from South African, Spanish and Swiss amphibians.

To assess the risk live animal importations have on facilitating wildlife epidemics (Smith et al. 2009), it is necessary to trace pathogen genotypes in both source and sink populations. A goal of the present study was to examine the diversity of $B d$ on cultivated, introduced and native L. catesbeianus using a combination MLST markers and rRNA ITS sequences. In addition, we survey for the first time $B d$ diversity on amphibians in the Atlantic Forest of Brazil, where bullfrogs are widely cultivated for the frog leg market. We identified a novel lineage of $B d$ ( $B d$-Brazil) in the Atlantic Forest of Brazil that is associated with the global trade in bullfrogs, is capable of sexual reproduction and is also detected on amphibians introduced into Japan. Our results add further support that the global movement of pathogen genotypes has been facilitated by an invasive, cultivated species of amphibian associated with the trade in frog legs.

\section{Materials and methods}

\section{Ethics statement}

All experiments involving animals were performed following protocols approved by the University of Maine Institutional Animal Care and Use Committee (Protocols A98-09-03 and A2001-09-01).

\section{Molecular diagnosis of $\mathrm{Bd}$ in US markets}

To determine the infection status of amphibians collected from wet markets in this study, we analysed 47 Lithobates catesbeianus individuals from 13 shops in seven US cities during 2009-2010 (Table 1). The authors purchased legs of living frogs from markets and kept them on ice until they could be returned to the laboratory where they were swabbed with a MW100 dry swab (Medical Wire and Equipment Company). DNA was extracted from the swabs using PrepMan Ultra (Applied Biosystems) 
Table 1 Percentage of US market shops and Lithobates catesbeianus demonstrating $B d$ infection

\begin{tabular}{lcc}
\hline City & $\begin{array}{l}\text { Shops: \% } \\
\text { infected }(n)\end{array}$ & $\begin{array}{l}\text { Frogs: \% } \\
\text { infected }(n)\end{array}$ \\
\hline Ypsilanti, MI & $100(1)$ & $100(4)$ \\
Boston, MA & $100(1)$ & $67(3)$ \\
Miami, FL & $0(1)$ & $0(3)$ \\
Atlanta, GA & $100(2)$ & $50(6)$ \\
Detroit, MI & $50(2)$ & $33(6)$ \\
Los Angeles, CA* & $100(1)$ & $20(10)$ \\
Chicago, IL & $40(5)$ & $20(15)$ \\
Averages (\%) & 70 & 41 \\
\hline
\end{tabular}

Samples were obtained between 2009-2010.

*Previously identified $B d$ positive shop (Schloegel et al. 2009).

following an established protocol (Retallick et al. 2006). $B d$ was detected in swab extracts with primers specific to the ribosomal rRNA ITS region (Annis et al. 2004) with GoTaq Green (Promega). PCR amplicons were electrophoresed on a $1 \%$ agarose gel and stained with GelRed (Biotium).

\section{Culture isolation}

Freshly killed L. catesbeianus on sale for human consumption in US markets were kept cold and transported to the laboratory for analysis and isolation using standard techniques (Longcore 2000). Fifteen strains were newly isolated for these studies, including the first from L. catesbeianus purchased from US markets and the first from native Brazilian amphibians. All isolates have been cryopreserved to ensure genotypic stasis (Boyle et al. 2003).

\section{Molecular markers and DNA sequencing}

We genotyped 45 strains (Table 2) at 36 loci (Table 3). Seventeen of these loci have been reported in previous studies (Morgan et al. 2007; James et al. 2009). The additional loci were chosen to be more polymorphic than previous loci by targeting regions identified by genome resequencing of six strains that were associated with chromosomal regions polymorphic for longdistance loss of heterozygosity ( $\mathrm{LOH}$ ) events (Cuomo and James unpublished). Primers for the new markers are listed in Table S1 (Supporting information); the protocol for amplification of these loci is similar to previous methods (James et al. 2009), but with $54{ }^{\circ} \mathrm{C}$ annealing and the proofreading PCR enzyme ExTaq (Takara). SNPs in the markers were detected by direct Sanger DNA sequencing of PCR amplicons at the U. Michigan Sequencing Core, and the matrix of genotypes can be found as Data S1 (Supporting information).
Partial ITS1 rRNA spacer amplicons were sequenced with primers Bd1a and Bd2a (Annis et al. 2004). The full-length ITS region, including the $5.8 \mathrm{~S}$ gene region, was amplified from DNA extracts of cultures with primers ITS1 and ITS4 (White et al. 1990). Amplicons of $B d 1 a$ and Bd2a were directly sequenced, and amplicons of ITS1 + ITS4 were cloned into pCR4-TOPO (Invitrogen). Subclones were sequenced after being PCR amplified with M13 primers.

ITS sequences of strains JEL423 and JAM81 were retrieved from the GenBank trace archive. The reads were identified as belonging to the ITS region by BLAST searching with the complete ITS sequence of JEL197 (AY997031), yielding 637 hits to the trace archive with $P$ value of $\left(P<10^{-180}\right)$. These sequences were assembled into clean sequence types using SEQUENCHER 4.10 .1 by trimming for quality, and after trimming to only sequences that matched the entire length of the PCR fragment, we excluded the sequence types that were found only a single time, leaving 122 reads and 20 types.

\section{Measurements of zoospore size and DNA content}

Zoospores were prepared for measurement of nuclear content by harvesting synchronized cultures started from zoospores grown on 1\% tryptone agar for 35 days in the presence of a thin layer of $\mathrm{H}_{2} \mathrm{O}$. Zoospores were harvested by flooding Petri dishes with distilled water and pelleted by centrifugation $(1800 \mathrm{~g})$. Spores were resuspended in $1 \times$ PBS at $1 \times 10^{6}$ zoospores $/ \mathrm{mL}$, fixed with an equal volume of ethanol and then pelleted. The pellet was resuspended in staining solution comprised of propidium iodide (PI: $50 \mu \mathrm{g} / \mathrm{mL}$ ) and RNAse A $(100 \mu \mathrm{g} / \mathrm{mL})$ in $1 \times$ PBS. Samples were run on a BD Biosciences FACSCalibur at the U. Michigan Flow Cytometry Core Facility. The external reference standard to which all other strains were compared was the PI histogram of strain JEL423, with DNA content estimated as the mode PI intensity of $c .10000$ zoospores. Comparisons of eight samples independently harvested, fixed, stained and run on two different occasions demonstrated an $r^{2}$ of $0.907(P<0.001)$, suggesting values could be compared across runs. This was done by standardizing each value relative to the value of JEL423 from the same run. Zoospore size was estimated from digital photographs taken of 50 zoospores from 3- to 5 -day-old 1\% tryptone agar cultures using an AxioCam MRc and AxioImager.A2 microscope (Zeiss) and analysed using AxioVision Rel. 4.7.

\section{Data analysis}

We assembled forward and reverse reads for consensus sequence building and SNP identification with SEQUENCHER 
Table 2 Geographic origin of $B d$ strains analysed in this study

\begin{tabular}{|c|c|c|c|c|}
\hline Strain & $\begin{array}{l}\text { Year } \\
\text { isolated }\end{array}$ & Geographic origin & Host & Collector \\
\hline CLFT 021/01 & 2010 & Serra do Japi mountain range, São Paulo, Brazil & Non-identified tadpole & L. F. Toledo, C. A. Vieira \\
\hline CLFT $023 / 00$ & 2011 & Monte Verde, Camanducaia, MG, Brazil & Hypsiboas sp. & L. F. Toledo, C. A. Vieira \\
\hline CLFT 024/02 & 2011 & Estrada da Graciosa, Morretes, PR, Brazil & Hylodes cardosoi & L. F. Toledo, C. A. Vieira \\
\hline CW34 & 2005 & Namaqualand, South Africa & Xenopus laevis & C. Weldon \\
\hline CW36 & 2005 & Port Elizabeth, South Africa & Amietia fuscigula & C. Weldon \\
\hline $\begin{array}{l}\text { Gibbo river - } \\
\text { Llesueruri- } \\
\text { 00-LB-1 = } \\
\text { Me00LB }\end{array}$ & 2000 & Gibbo River, Victoria, Australia & Litoria lesueurii & L. Berger \\
\hline JEL197 & 1997 & National Zoological Park, DC, USA (zoo) & Dendrobates azureus & J. E. Longcore \\
\hline JEL213 & 1998 & Mono Co., CA, USA & Lithobates muscosa & G. Fellers \\
\hline JEL225 & 1998 & Africa (from captive population in WI, USA) & Silurana tropicalis & L. Northy \\
\hline JEL230 & 1999 & Montrose Canyon, AZ, USA & Lithobates yavapaiensis & M. Sredl \\
\hline JEL231 & 1999 & Mesquite Wash, AZ, USA & L. yavapaiensis & M. Sredl \\
\hline JEL239 & 1999 & Ghana (imported) & Silurana tropicalis & B. Stubbs \\
\hline JEL253 & 1998 & Melbourne, Vic., Australia (captive) & Limnodynastes dumerilii & L. Berger \\
\hline JEL258 & 1999 & Orono, ME, USA & Lithobates sylvaticus & J. E. Longcore \\
\hline JEL261 & 1999 & $\begin{array}{l}\text { Mont Saint-Hilaire Biosphere Reserve, Quebec, } \\
\text { Canada }\end{array}$ & Lithobates catesbeianus & I. Mikaelian \\
\hline JEL270 & 1999 & Point Reyes, CA, USA & L. catesbeianus & G. Fellers \\
\hline JEL275 & 1999 & Colorado, USA & Anaxyrus boreas & M. Jones \\
\hline JEL277 & 1999 & Arizona, USA & Ambystoma tigrinum & E. Davidson \\
\hline JEL282 & 2000 & Toledo Zoo, OH, USA (zoo) & Anaxyrus americanus & Anon. \\
\hline JEL289 & 2000 & Milford, ME, USA & Lithobates pipiens & J. E. Longcore \\
\hline JEL307 & 2001 & National Zoological Park, DC, USA (zoo) & Bufo guttatus & J. E. Longcore \\
\hline JEL360 & 2002 & Bethel, ME, USA & L. catesbeianus & J. R. Longcore \\
\hline JEL423 & 2004 & Guabal, Panama & Phyllomedusa lemur & J. E. Longcore \\
\hline JEL428 & 2005 & Venezuela & L. catesbeianus & B. Han, M. Lampo \\
\hline JEL626 & 2009 & Finley National Wildlife Refuge, OR, USA & L. catesbeianus & T. Chesnutt \\
\hline JEL627 & 2009 & Bethel, ME, USA & L. catesbeianus & J. R. Longcore \\
\hline JEL630 & 2009 & Finley National Wildlife Refuge, OR, USA & L. catesbeianus & T. Chesnutt \\
\hline JEL644 & 2010 & Lowden Meadows Dredge Ponds, California, USA & L. catesbeianus & J. Bettaso \\
\hline JEL646 & 2010 & Point Reyes, CA, USA & Pseudacris regilla & P. Kleeman, G. Fellers \\
\hline JEL647 & 2010 & Point Reyes, CA, USA & P. regilla & P. Kleeman, G. Fellers \\
\hline JEL648 & 2010 & Serra do Japi mountain range, São Paulo, Brazil & Hylodes ornatus & L. F. Toledo, C. A. Vieira \\
\hline JEL649 & 2010 & Serra do Japi mountain range, São Paulo, Brazil & H. ornatus & L. F. Toledo, C. A. Vieira \\
\hline JEL656 & 2010 & Point Reyes, CA, USA & Lithobates pipiens & J. Bettaso \\
\hline JSOH-1 & 2008 & Toledo, OH, USA & L. pipiens & J. Scott \\
\hline LMS902 & 2008 & Pindamonhangaba, São Paulo, Brazil (farm) & L. catesbeianus & L. M. Schloegel \\
\hline LMS925 & 2008 & Pindamonhangaba, São Paulo, Brazil (farm) & L. catesbeianus & L. M. Schloegel \\
\hline LMS929 & 2008 & Belém, Pará, Brazil (farm) & L. catesbeianus & L. M. Schloegel \\
\hline LMS931 & 2009 & Tremembé, São Paulo, Brazil (farm) & L. catesbeianus & L. M. Schloegel \\
\hline LMS933 & 2009 & New York, NY, USA (market) & L. catesbeianus & L. M. Schloegel \\
\hline LMS934 & 2009 & New York, NY, USA (market) & L. catesbeianus & L. M. Schloegel \\
\hline PM1 & 2001 & Panama & Pristimantis caryophyllaceus & P. J. Murphy \\
\hline PM5 & 2001 & Panama & Smilisca phaeota & P. J. Murphy \\
\hline PTH-001 & 2009 & Victoria, BC, USA & L. catesbeianus & F. Hamilton \\
\hline SRS810 & 2006 & Savannah River, SC, USA & L. catesbeianus & L. M. Schloegel \\
\hline UM142 & 2009 & Ypsilanti, MI, USA (market) & L. catesbeianus & T. Y. James \\
\hline
\end{tabular}

4.10.1 (GeneCodes). Clustering of genotypes by neighbour-joining was done using genetic distance matrices calculated by combining each variable site $(n=126)$ within the 36 MLST locus data set into one matrix and estimating genetic distance among genotypes using hetequal coding
(Mountain \& Cavalli-Sforza 1997; James et al. 2009). The present analyses utilize the information on distance between alleles within an MLST locus unlike our previous analyses in which each MLST locus encoded only two alleles. Trees were estimated using PAUP v4.0b10 
Table 3 Summary of per locus genetic variation across all samples

\begin{tabular}{|c|c|c|c|c|}
\hline Locus & Location & \# Alleles & $H_{\mathrm{O}}$ & $F_{\mathrm{IS}}^{*}$ \\
\hline $6873 X 2$ & sc1: $0.31 \mathrm{Mbp}$ & 3 & 0.400 & 0.155 \\
\hline $8392 X 2$ & sc1: $0.36 \mathrm{Mbp}$ & 3 & 0.378 & 0.232 \\
\hline $8009 X 2$ & sc1: $0.64 \mathrm{Mbp}$ & 4 & 0.533 & -0.094 \\
\hline $6677 X 2$ & sc1: $0.73 \mathrm{Mbp}$ & 2 & 0.467 & -0.026 \\
\hline b7-10c & sc1: $0.82 \mathrm{Mbp}$ & 4 & 0.533 & -0.103 \\
\hline BDC5 & $\mathrm{sc} 1: 1.45 \mathrm{Mbp}$ & 3 & 0.533 & -0.544 \\
\hline $8329 X 2$ & $\mathrm{sc} 1: 1.60 \mathrm{Mbp}$ & 2 & 0.622 & -0.337 \\
\hline BdSC1.2 & $\mathrm{sc} 1: 2.00 \mathrm{Mbp}$ & 3 & 0.844 & -0.672 \\
\hline BdSC1.2.4 & $\mathrm{sc} 1: 2.43 \mathrm{Mbp}$ & 4 & 0.422 & -0.215 \\
\hline BDC24 & $\mathrm{sc} 1: 2.75 \mathrm{Mbp}$ & 3 & 0.356 & -0.279 \\
\hline $9893 X 2$ & $\mathrm{sc} 1: 4.31 \mathrm{Mbp}$ & 2 & 0.067 & 0.787 \\
\hline BdSC2.02 & $\mathrm{sc} 2: 0.21 \mathrm{Mbp}$ & 4 & 0.711 & -0.447 \\
\hline BdSC3.1 & sc3: $0.17 \mathrm{Mbp}$ & 3 & 0.333 & 0.284 \\
\hline BdSC3.9 & sc3: $0.97 \mathrm{Mbp}$ & 2 & 0.578 & -0.315 \\
\hline BdSC4.3 & sc4: $0.32 \mathrm{Mbp}$ & 3 & 0.111 & -0.155 \\
\hline BdSC4.16 & sc4: $1.64 \mathrm{Mbp}$ & 3 & 0.600 & -0.257 \\
\hline BdSC5.1 & sc5: $0.12 \mathrm{Mbp}$ & 3 & 0.659 & -0.364 \\
\hline BdSC5.6.1 $1^{+}$ & sc5: $0.61 \mathrm{Mbp}$ & 3 & 0.889 & -0.798 \\
\hline BdSC5.6.2 ${ }^{+}$ & sc5: $0.61 \mathrm{Mbp}$ & 2 & 0.844 & -0.696 \\
\hline APRT13 & sc5: $0.77 \mathrm{Mbp}$ & 4 & 0.911 & -0.792 \\
\hline R6046 & sc5: $1.22 \mathrm{Mbp}$ & 2 & 0.244 & -0.395 \\
\hline BdSC6.2 & sc6: $0.23 \mathrm{Mbp}$ & 3 & 0.227 & -0.592 \\
\hline BdSC6.6. $1^{+}$ & sc6: $0.64 \mathrm{Mbp}$ & 2 & 0.818 & -0.793 \\
\hline BdSC6.6. $2^{+}$ & sc6: $0.64 \mathrm{Mbp}$ & 2 & 0.841 & -0.851 \\
\hline BdSC6.15 & sc6: $1.51 \mathrm{Mbp}$ & 4 & 0.178 & 0.060 \\
\hline BdSC7.6 & sc7: $0.66 \mathrm{Mbp}$ & 2 & 0.578 & -0.800 \\
\hline BdSC8.10 & sc8: $0.98 \mathrm{Mbp}$ & 3 & 0.111 & 0.104 \\
\hline BdSC9.7 & sc9: $0.68 \mathrm{Mbp}$ & 3 & 0.933 & -0.827 \\
\hline $8702 X 2$ & sc9: $0.14 \mathrm{Mbp}$ & 2 & 0.689 & -0.523 \\
\hline 6164Y2 & sc10: $0.27 \mathrm{Mbp}$ & 2 & 0.778 & -0.620 \\
\hline mb-b13 & sc10: $0.41 \mathrm{Mbp}$ & 2 & 0.844 & -0.846 \\
\hline BDC18. $1^{+}$ & sc11: $0.46 \mathrm{Mbp}$ & 4 & 0.778 & -0.554 \\
\hline $\mathrm{BDC} 18.2^{+}$ & sc11: $0.46 \mathrm{Mbp}$ & 2 & 0.711 & -0.538 \\
\hline BdSC12.4 & sc12: $0.37 \mathrm{Mbp}$ & 2 & 0.733 & -0.570 \\
\hline CTSYN1 & sc15: $0.12 \mathrm{Mbp}$ & 2 & 0.756 & -0.640 \\
\hline HMG17 & sc17: $0.13 \mathrm{Mbp}$ & 4 & 0.844 & -0.672 \\
\hline
\end{tabular}

Location refers to the supercontig (sc) in the Broad Institute's assembly of JEL423 (accessed November 2011) followed by position within the contig rounded to the closest $10 \mathrm{kbp}$. Supercontigs are ordered in descending size from sc1 (4.44 Mbp) to sc17 (0.24 Mbp). $H_{\mathrm{O}}$ measures the observed heterozygosity and $F_{\mathrm{IS}}$ is the inbreeding coefficient (deviation within populations from heterozygosity expected under random mating). Primer sequences can be found in previous publications (Morehouse et al. 2003; James et al. 2009) and Table S1 (Supporting information).

${ }^{*} \mathrm{~F}_{\mathrm{IS}}$ is a global estimate across three populations ( $B d-\mathrm{GPL}-1, B d-$ GPL-2, Bd-Brazil).

${ }^{+}$These loci represent cases in which a single PCR sequenced region did not show complete linkage disequilibrium and determining phase was ambiguous, and thus, the loci have been divided into two loci grouping sites displaying complete linkage disequilibrium together.
(Swofford 2002) with support measures generated using 1,000 bootstrap pseudo-replicates. We also visualized clustering with a principal components analysis (PCA) using the R packages ADE4 (Dray \& Dufour 2007) and ADEGENET (Jombart 2008).

Estimates of observed heterozygosity $\left(H_{\mathrm{O}}\right)$ gene diversity or expected heterozygosity $\left(H_{\mathrm{E}}\right)$ and inbreeding coefficients $\left(F_{\mathrm{IS}}\right)$ were measured using GENEPOP 4.0.10 (Raymond \& Rousset 1995). Confidence intervals for heterozygosity within populations was estimated by bootstrapping across loci using a simple script as previously implemented (James et al. 2009).

To test the hybrid origin of strain CLFT024-02, we implemented a Bayesian approach (NEWHYBRIDS) that identifies putative hybrids from a sample even when the allele frequencies of parental populations are unknown (Anderson \& Thompson 2002). Their method uses model-based clustering to compute, by Markov chain Monte Carlo (MCMC), the posterior probability (PP) that an individual belongs to a parental class or a recent hybrid class (e.g. F1, F2, F3 or backcross BC-1). For example, F2 hybrids are expected to be comprised of $1 / 2$ loci that are heterozygous for the alleles from the two parental populations and $1 / 4$ of loci homozygous for alleles from each of the parental populations. Three analyses were performed. In the first, prior probabilities were set to uninformative for all isolates except the putative parental Brazilian strains [CLFT021-00 (P1:BdGPL), CLFT023-00 (P1:Bd-GPL), JEL648 (P2:Brazil), JEL649 (P2:Brazil)] which were set to $100 \%$ pure parental. In a second analysis, we ran the MCMC without prior probabilities on any strain classes. The final analysis also initiated the run without priors on strains but only used the strains from Brazil. The runs were initiated with Jeffreys priors and run for an initial burn-in of 50,000 sweeps followed by sampling over 500,000 sweeps. For each analysis, individuals were classified into one of nine genotype categories: parental type-1, parental type-2, F1, F2, F3, BC-1.1 (e.g. backcross-1 to parent 1), BC-1.2, BC-2.1 and BC-2.2.

The alignment of ITS rRNA sequences was manually constructed in MACCLADE 4.08 (Maddison \& Maddison 2000), and the ITS phylogeny was estimated with PHYML v2.4.4 (Guindon \& Gascuel 2003). The best fitting model of substitution $(\mathrm{TN} 93+\mathrm{G})$ for analysis was selected using the Akaike Information Criterion in JMODELTEST 0.1.1 (Posada 2008). Gene genealogies of individual MLST loci and their branch lengths were estimated under parsimony using DNAPARS of the PHYLIP package (Felsenstein 1989). The number of ITS sequence types in strain UM142 was estimated by sample-based rarefaction using the classic Chao 1 formula with EstimateS (Colwell 1997) after collapsing together 
sequences differing by two nucleotides or fewer to eliminate possible PCR-generated mutations. Phylogenetic diversity and rarefaction analysis for groups of ITS sequences were calculated using the MOTHUR package (Schloss et al. 2009).

\section{Results}

$\mathrm{Bd}$ is widely present in US markets

We detected $B d$ infection from food markets that sell live L. catesbeianus in five previously unreported US cities (Table 1). In combination with a previous study (Schloegel et al. 2009), the overall Bd incidence on bullfrogs is $41-62 \%$ in US markets. We cultured $B d$ from frogs purchased in New York, NY (LMS933, LMS934) and Ypsilanti, MI (UM142) and analysed these strains together with a global sample of strains, including four strains from Brazilian bullfrog farms, three strains from bullfrogs purchased in the USA, six strains from invasive bullfrog populations and five strains from native anurans from the southern Atlantic Forest in Brazil where L. catesbeianus is widely farmed (Table 2). Using these 45 strains and a set of 36 MLST markers, we detected genetic structure within the $B d$-GPL, evidence for novel genotypes and evidence for sexual reproduction between genotypes.

\section{Novel Bd genotypes from Brazil}

In contrast to previous MLST studies that detected only two alleles at each of the loci (Morehouse et al. 2003; James et al. 2009), 1-2 new alleles at 21/36 loci were detected among four strains with novel $B d$ genotypes (Bd-Brazil). These novel genotypes are highly distinct (100\% bootstrap support) by genetic clustering algorithms (Fig. 1) and PCA (Fig. 2). The four Bd-Brazil genotypes include a strain from Lithobates catesbeianus sold in a market in Michigan (UM142) and three native frogs from the Atlantic Forest in Brazil (JEL648, JEL649, CLFT024/02). One of these (CLFT024/02) appears to be a hybrid as discussed later.

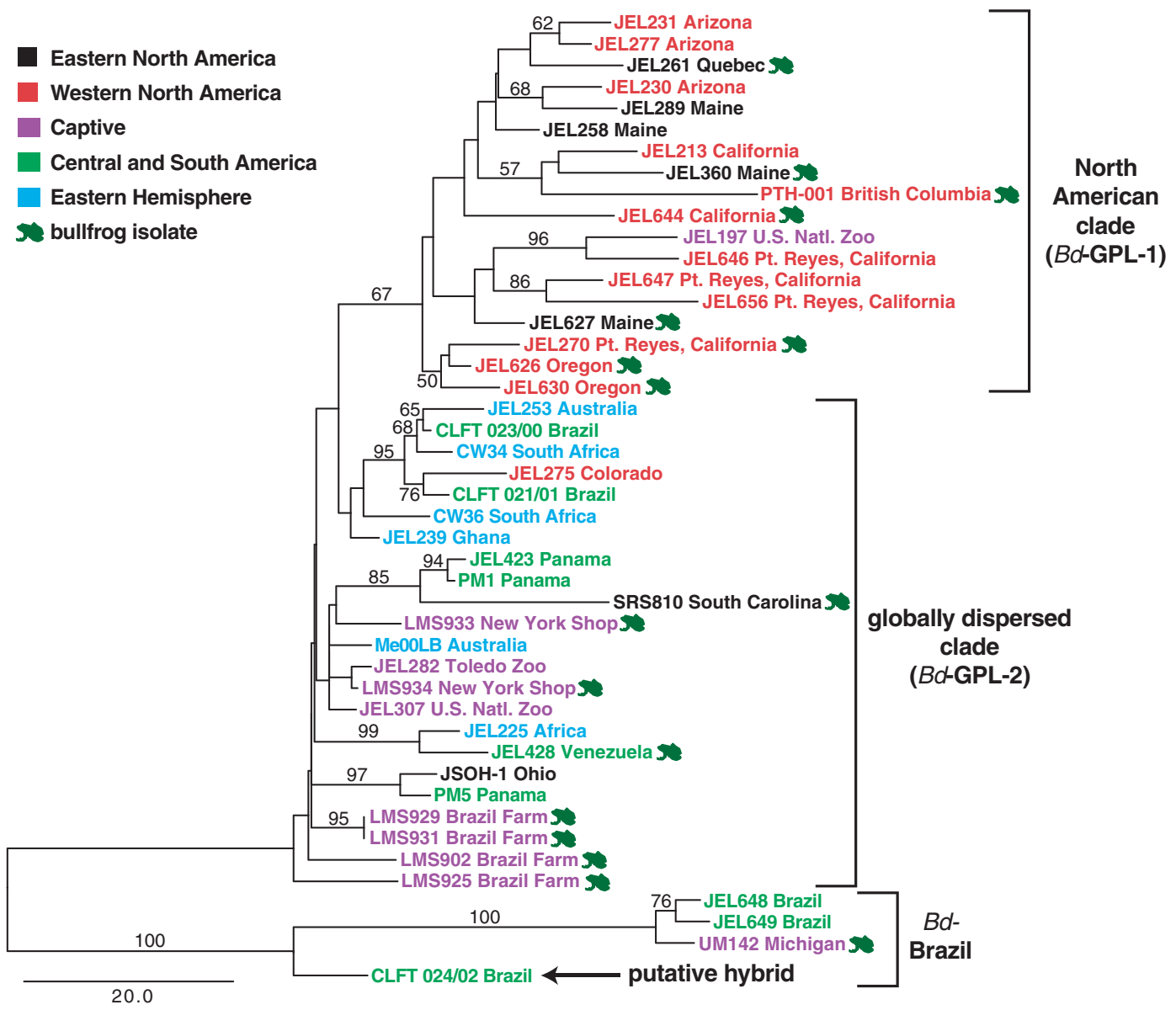

Fig. 1 Neighbour-joining dendrogram of $B d$ strains based on 36 multi-locus sequence typing loci. Bootstrap percentages out of 1000 pseudo-replicates are shown for nodes with values above $50 \%$. 


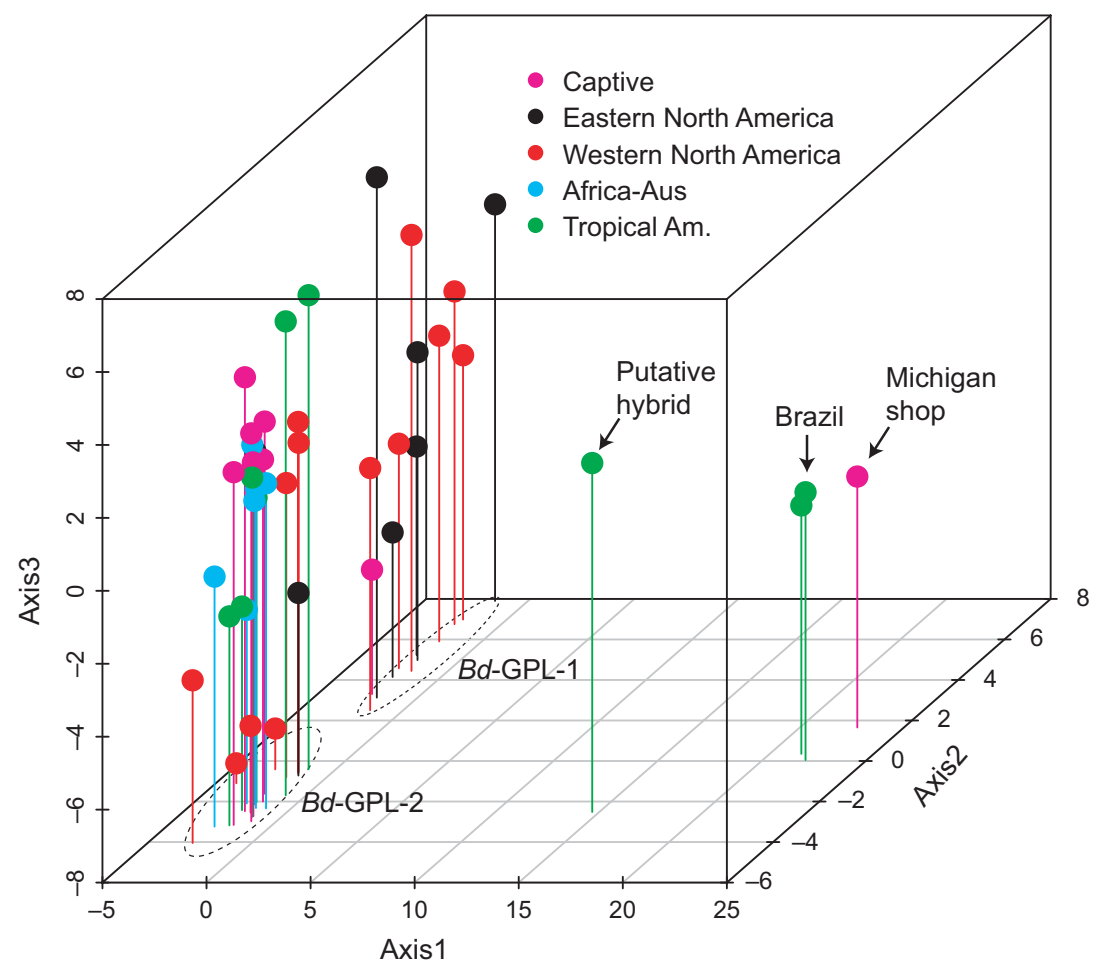

Fig. 2 Principal components analysis plot (Dray \& Dufour 2007; Jombart 2008) of the $45 B d$ strains using the multi-locus sequence typing data. Axis 1 explains $41 \%$ of the variation, Axis 2 explains $11 \%$, and Axis 3 explains $9 \%$.

All other strains isolated from bullfrogs strains were similar to previously detected Bd-GPL genotypes (Fig. 1). The Bd-GPL genotypes could also be divided into two subpopulations based on principal components Axis 2, a group exclusively comprised of North American strains ( $B d$-GPL-1) and a globally dispersed group (Bd-GPL-2) (Fig. 2). This distinction was statistically supported by bootstrap analysis and neighbour-joining clustering (Fig. 1). The Bd-GPL-2 cluster corresponds with the most geographically diverse and genetically similar group of strains (e.g. Africa, Australia, North America and Panama) and includes strains from multiple captive anurans from zoos and bullfrogs from farms and markets. All of the market strains, farm strains and Atlantic Forest Brazilian strains that were not of the $B d$-Brazil genotype were part of the Bd-GPL-2 group. The Bd-GPL-1 cluster comprises isolates from throughout North America including bullfrog strains from the western and eastern United States.

As reported previously (James et al. 2009) loci varied over a wide range of observed heterozygosities and inferred inbreeding coefficients (Table 3). Most of these values are strongly consistent with predominately asexual reproduction because $F_{\text {IS }}$ values are highly negative. We compared genetic diversity between the Bd-GPL-1, $B d$-GPL-2 and Bd-Brazil clusters to identify whether any
Table 4. Population mean diversity

\begin{tabular}{|c|c|c|c|c|}
\hline & $n$ & $\begin{array}{l}\text { Mean \# } \\
\text { alleles } \\
\text { per locus }\end{array}$ & $H_{\mathrm{O}}$ & $F_{\mathrm{IS}}$ \\
\hline Total & 45 & 2.81 & 0.580 & -0.175 \\
\hline $\begin{array}{l}\text { Global Panzootic } \\
\text { Clade } 1 \text { (Bd-GPL-1) }\end{array}$ & 12 & 1.94 & 0.601 & -0.321 \\
\hline $\begin{array}{l}\text { Global Panzootic } \\
\text { Clade } 2 \text { (Bd-GPL-2) }\end{array}$ & 29 & 1.89 & 0.599 & -0.469 \\
\hline$B d$-Brazil & 3 & 1.42 & 0.296 & -0.488 \\
\hline Bullfrog ( $B d$-GPL) & 16 & 2.00 & 0.637 & -0.390 \\
\hline Nonbullfrog (Bd-GPL) & 25 & 2.00 & 0.575 & -0.322 \\
\hline
\end{tabular}

Bd-GPL-1 and Bd-GPL-2 are divided according to the tree shown in Fig. 1. The putative hybrid CLFT024-02 is not included in any group except total. Bullfrog and nonbullfrog data sets only include $B d$-GPL strains.

$n$, number of strains; GPL, global panzootic lineage.

of the groups were more heterozygous. The most striking difference was the lower heterozygosity of $B d$-Brazil genotypes (Table 4). However, because the MLST markers were targeted towards markers polymorphic between GPL genotypes, this difference is likely due to ascertainment bias (Rosenblum \& Novembre 2007). Within $B d$-GPL genotypes, bullfrog isolates had significantly higher heterozygosity $\left(H_{\mathrm{E}}\right.$ and $\left.H_{\mathrm{O}}\right)$ than 
nonbullfrog isolates, as previously reported (James et al. 2009) (Table 4).

\section{Strain CLFT024/02 is produced from recombination between Bd-GPL and Brazil genotypes}

The evidence that CLFT024/02 is the product of sexual reproduction between the $B d$-GPL and the $B d$ Brazil genotypes is clear. Specifically, the three pure $B d$-Brazil genotypes have no shared alleles ( $B d$-Brazilspecific alleles) with the Bd-GPL strains at 17 loci. The putative hybrid has a diploid genotype that pairs one of the $B d$-Brazil-specific alleles with one of the $B d$-GPL-specific alleles at 14 of these 17 loci. To eliminate the possibility that CLFT024/02 was a mixed culture of multiple genotypes, we isolated a single sporangium from the culture, re-genotyped the subculture and recovered the same genotype. Additional support for the hybrid nature of this strain was found using the programme NEWHYBRIDS. When setting priors for four of the putative parental genotypes, the resulting PP of CLFT024/02 assignment strongly suggested a first-generation backcross to a $B d$-Brazil genotype $(99.3 \%)$ with all other genotypes (such as pure parental and F1 with a PP $<0.4 \%$ ). In the absence of priors for any individuals the $B d$-Brazil genotypes (UM142, JEL648, JEL649) and CLFT024/02 were all assigned to one parental population and all of the $B d-$ GPL isolates to be classified as one of several hybrid genotypes (F1, F2 and BC). Finally, when only considering the nine Brazilian strains and in the absence of any priors, the $B d$-Brazil genotypes (JEL648, JEL649) were classified as parental type-1 with PP $>99.9 \%$, the $B d$-GPL strains classified as parental type-2 (CLFT021/01, CLFT023/00, LMS902, LMS925, LMS929, LMS931) with PP $>99.9 \%$ and the putative hybrid CLFT024/02 classified as a backcrossed hybrid to parental type-1 with PP > 95\%.

\section{Bd-Brazil genotypes show reduced DNA content}

We estimated the DNA content of the asexual zoospores of 29 strains by flow cytometry using the nuclear stain PI. DNA content (measured as mode value of PI staining of c. 10,000 zoospores) ranged greater than twofold: JEL423 (Bd-GPL genotype from Panama) zoospores contained roughly twice as much DNA as spores from JEL648 and UM142 (Bd-Brazil genotypes), whereas other strains (e.g. JEL270; $B d$-GPL from California) possessed intermediate levels (Fig. 3). We measured zoospore diameter on microscopy images of the same strains to compare with DNA content. Spore size was positively correlated with DNA content $\left(r^{2}=0.389 ; P<0.001\right)$, and the three strains with the
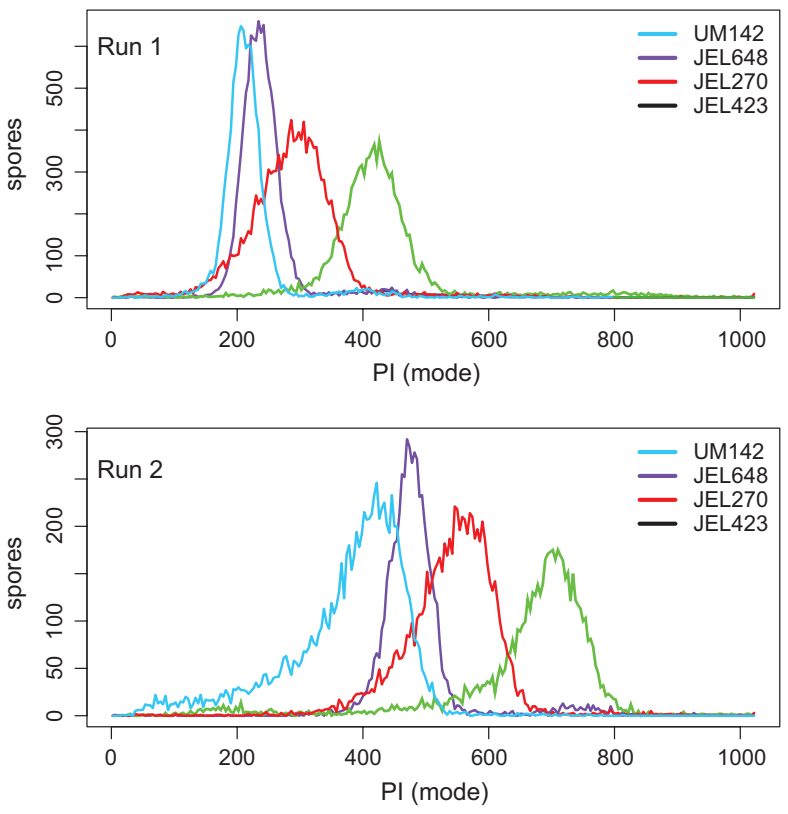

Fig. 3 DNA content differs among genotypes. Shown are the histograms of nucleic acid content with propidium iodide (PI) staining of the zoospores of four strains from two independent analyses. Included are two strains of $B d$-Brazil genotype (UM142 and JEL648), a strain from Point Reyes, CA, USA in 1999 (JEL270), and a strain from Panama in 2004 (JEL423). Because PI values are arbitrarily scaled, these independent runs vary in scale but are consistent in rank order.

highest DNA content had among the largest measured spore diameters (Fig. 4). Bd-GPL genotypes had a wide range of DNA content, whereas $B d$-Brazil and genotypes were of a consistently lower DNA content (Fig. 4). Finally, the DNA content of the putative hybrid was estimated and found to be intermediate between $B d$-Brazil and at the high end of Bd-GPL genotype means.

\section{Novel genotypes or novel species?}

Because of the large genetic distance between $B d$-Brazil and $B d$-GPL genotypes, the question arises as to whether they represent a new species of Batrachochytrium or are drawn from the same gene pool. We investigated this question by testing whether the $B d$-Brazilspecific alleles are more similar to each other (reciprocally monophyletic) than they are to $B d$-GPL alleles by constructing phylogenies for all of the alleles at each locus. Shown in Fig. S1 (Supporting information) are the genealogies of each of the loci with three or more alleles. There is no evidence for consistently greater genetic distance between the alleles found in the $B d$ GPL strains and the alleles newly observed in the $B d$-Brazil strains. However, of the seven loci in which 


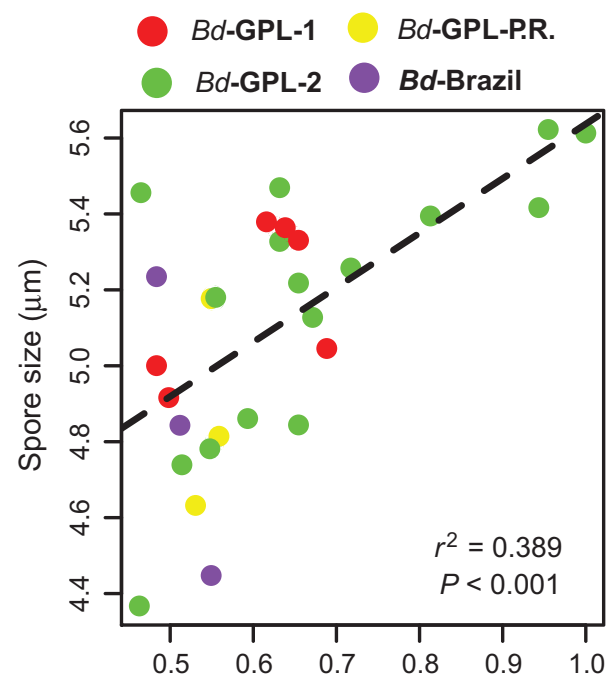

Fig. 4 Spore size is correlated with DNA content per spore. Scatterplot comparing spore size and DNA content (mode of c. $10^{4}$ spores relativized to strain JEL423 for each independent run) for 28 strains. Spore size as measured by microscopy from cultures of $B d$ grown on solid media was positively correlated with spore size from liquid cultures $\left(r^{2}=0.380, P<0.01\right)$, and mode of forward scatter values (using JEL423 as an external reference) by flow cytometry $\left(r^{2}=0.194, P<0.02\right)$, but spore size estimates from zoospores from solid media showed the lowest coefficient of variation.

there were four alleles, the two $B d$-Brazil alleles (labelled 3 and 4 in Fig. S1, Supporting information) are monophyletic in four of the single locus genealogies. This is greater than the random expectation of 2.3, but does not provide convincing evidence that the $B d-$ Brazil genotypes are a different species.

\section{Bd-Brazil genotypes are associated with Lithobates catesbeianus in Japan}

To compare the Bd-Brazil and Bd-GPL genotypes with the diverse genotypes reported in a previous study on $B d$ diversity in Japan based on ITS rRNA haplotypes (Goka et al. 2009), we PCR amplified the ITS region with universal primers and then subcloned and sequenced 24-48 clones for three strains: UM142 (USA), JEL648 (Brazil) and CW34 (South Africa). Additional ITS haplotypes were retrieved from genome sequencing studies of two strains, JEL423 (Panama) and JAM81 (California). Strains are not characterized by a single sequence; we recovered 9-22 distinct ITS haplotypes per strain. Based on rarefaction analysis (Colwell 1997), we estimated 43 distinct ITS haplotypes within the UM142 genome. A maximum likelihood phylogeny was constructed of the ITS haplotypes from full-length ITS sequences obtained from subcloning and genome sequencing projects. Although the distinction was not statistically supported, haplotypes from the $B d$-Brazil strains phylogenetically divergent from the $B d$-GPL haplotypes (Fig. 5).

We compared published Japanese $B d$ ITS haplotypes to our sequences by limiting the region of consideration in phylogenetic analysis to the small fragment used by Goka et al. (2009) and others for diagnostic PCR and sequencing. The phylogeny shows a separation between haplotypes from $B d$-Brazil genotype strains and Bd-GPL strains (Fig. 6, arrow). The Bd-Brazil clade includes many $B d$ ITS haplotypes from nonnative amphibians in Japan, almost exclusively L. catesbeianus. We then asked whether the phylogenetic diversity is greater for $B d$-Brazil, $B d$-GPL, invasive, or native Japanese ITS sequences by rarefaction analysis of unique haplotypes. ITS sequences from $B d$-Brazil (UM142 and JEL648) and native Japanese amphibians had similar diversity, while diversity of ITS sequences from amphibians invasive to Japan amphibians was the greatest, probably because these amphibians are infected with $B d$ from both $B d$-Brazil and $B d$-GPL ITS haplotype pools (Fig. S2, Supporting information). The diversity of ITS haplotypes subcloned from strain CW34 (South Africa) was influenced by the region of the sequence considered and was considerably lower in the smaller region (Fig. S2, Supporting information) than in the full-length region (Fig. 5).

\section{Discussion}

Since its discovery in 1998, the origin of the chytridiomycosis panzootic has been a mystery. Based on sequences of single copy genes, ribosomal RNA sequences and collection dates for infected museum specimens, various source populations for the epidemic have been suggested (Weldon et al. 2004; Goka et al. 2009; James et al. 2009), but unequivocal evidence as to the geographic origin of the disease has been lacking. Numerous studies have attempted to distinguish amphibian populations with endemic disease from populations in which the disease has been recently introduced (Rachowicz et al. 2005; Briggs et al. 2010; Kielgast et al. 2010). The data presented here, in combination with a recently published global population genomic survey (Farrer et al. 2011), suggests the genetic diversity of $B d$ is much greater than previously realized and includes endemic or genetically isolated populations of $B d$ whose common ancestor is minimally 750 years old (Farrer et al. 2011). Together, these results suggest that the fungus has infected amphibians long before the 20th century global amphibian declines were realized (Blaustein \& Wake 1990).

These results widen the geographic distribution of genotypes other than Bd-GPL to include South Africa, Spain, Switzerland, Japan and Brazil. It is unknown 


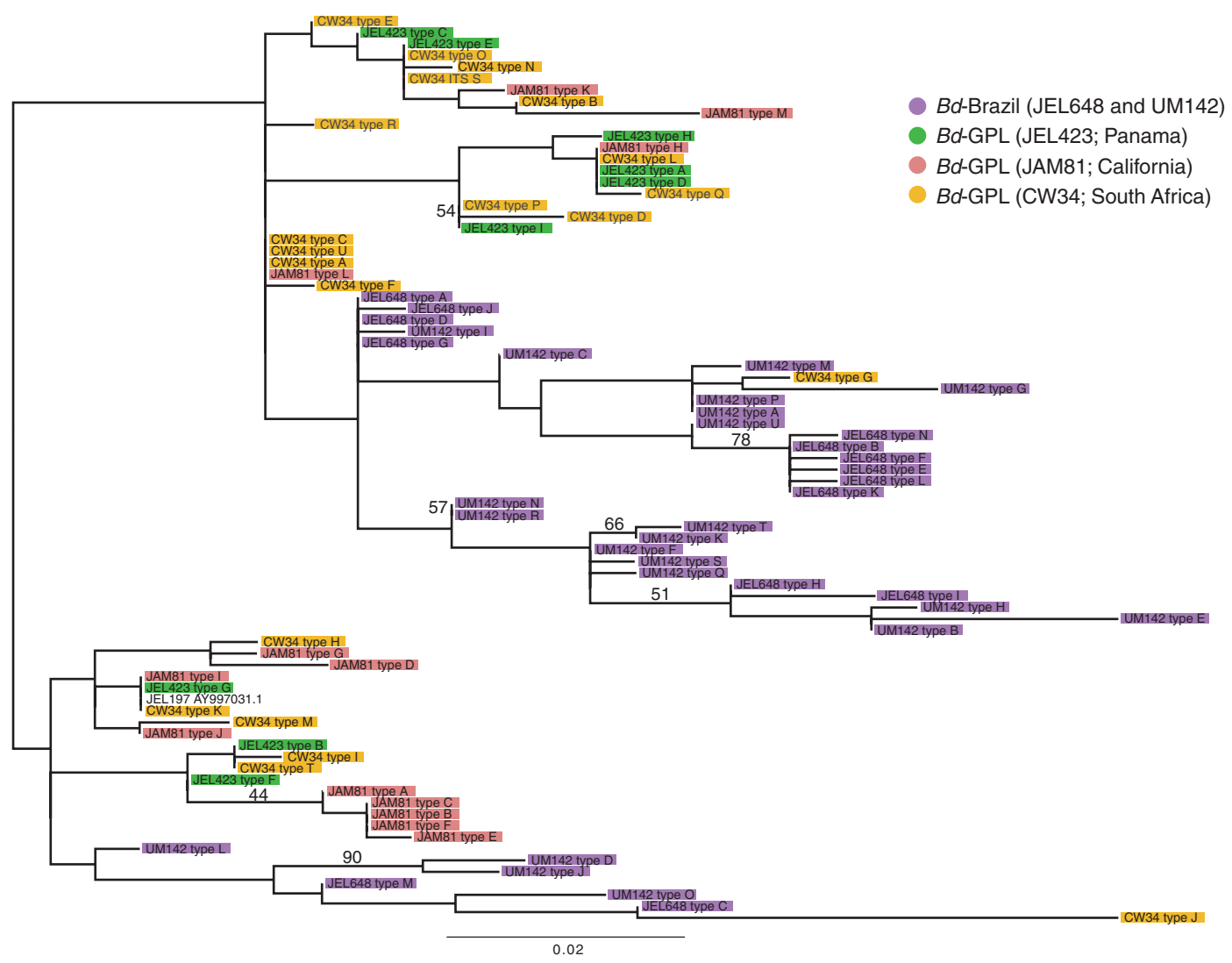

Fig. 5 Phylogeny of full-length internal transcribed spacer rRNA sequences from subcloned PCR products (UM142, JEL648, CW34) and genome sequencing projects (JAM81, JEL423). The phylogeny was constructed using maximum likelihood after removing ambiguously aligned regions. Bootstrap values (out of 1,000 pseudo-replicates) are shown only for branches with values greater than $40 \%$.

whether the Brazilian genotypes overlap with any of the novel genotypes reported by Farrer et al. (2011), but we are currently investigating this possibility. Because at least one of the putatively endemic genotypes (Bd-CAPE) has demonstrated attenuated virulence (Farrer et al. 2011), we hypothesize that the Bd-GPL has replaced endemic $B d$ genotypes as it spread throughout the world, probably facilitated by the global trade in amphibians. Most previous $B d$ genotyping has focused on regions of decline, such as the Sierra Nevada, Panama, Australia and Spain, and because panzootic genotypes may be more readily culturable relative to endemic strains, we hypothesize that our sampling and global perspective on $B d$ diversity has been biased towards virulent genotypes.

Our results suggest that movement of bullfrogs, whether intentional or accidental, has resulted in the invasion of Brazil and Japan by both the frogs and their associated $B d$ infections. In Japan, invasive Lithobates catesbeianus adults were infected with both the Bd-GPL and $B d$-Brazil ITS haplotypes, with the $B d$-Brazil haplotypes found almost exclusively on L. catesbeianus (Fig. 6). This suggests that on amphibians native to
Japan the $B d$-GPL may be able to outcompete sympatric $B d$-Brazil genotypes, whereas $B d$-Brazil can outcompete $B d$-GPL on L. catesbeianus in Japan. Given the exotic status of $L$. catesbeianus and the prevalence of Bd-Brazil haplotypes on their skin, it seems probable to assume that they brought the $B d$-Brazil genotypes to Japan during their invasion.

Both $B d$ and invasive $L$. catesbeianus are found widely in the coastal Atlantic Forest of Brazil where L. catesbeianus farms were established in the 1930s (Flores Nava 2005). Of the seven strains associated with L. catesbeianus in the food trade (either from farms or in shops) that were genotyped, six were $B d$-GPL-2 genotypes and a single one was a $B d$-Brazil genotype. Among the five strains isolated from native Brazilian frogs, two were of the $B d$-Brazil genotype, two were $B d$-GPL-2 genotypes and the fifth was a putative hybrid between these two lineages. Within Brazil, the southern states display extensive L. catesbeianus farming, invasive bullfrog populations and a high prevalence of $B d$ (Fig. 7). Long-term population data on the status of amphibians in Brazil is lacking, but the proximity of farmed and invasive L. catesbeianus to native herpetofauna may have 


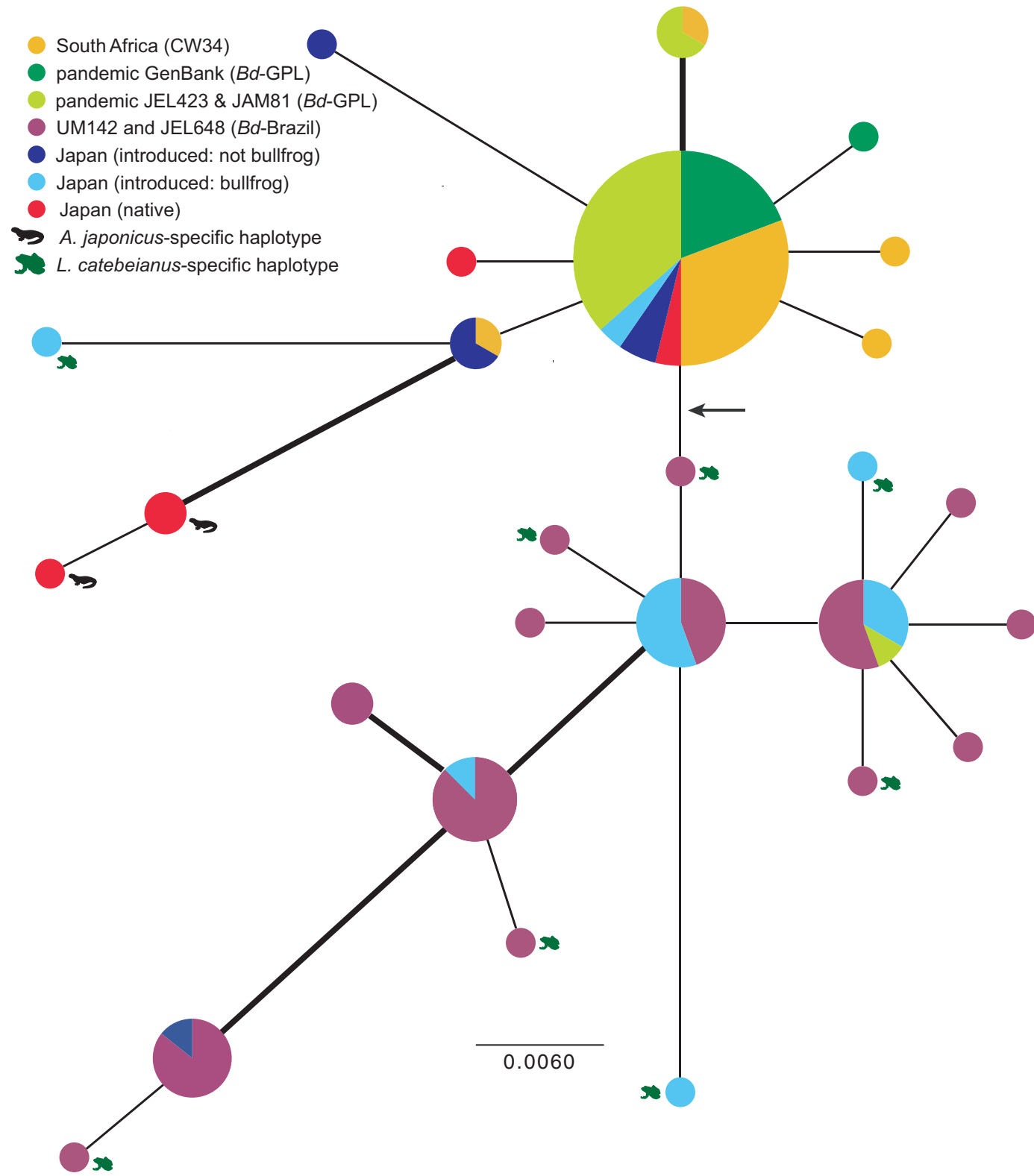

Fig. 6 Internal transcribed spacer (ITS) rRNA maximum likelihood phylogram links $B d$ strains with novel multi-locus sequence typing (MLST) genotypes with strains from invasive amphibian species in Japan. Tree comprises Japanese haplotypes of native and invasive amphibians from Goka et al. (2009), Bd-GPL haplotypes from genome sequencing projects (JEL423 and JAM81), Bd-GPL genotypes obtained from PCR products retrieved from GenBank, South African haplotypes subcloned from CW34 ITS PCR products, and subcloned haplotypes from Bd-Brazil genotype PCR products (JEL648, UM142). Japanese haplotypes recovered from both bullfrogs and other species are indicated here only as from bullfrogs (three instances). The areas of the circles are proportional to the number of sequences of identical haplotype. Only the region between the primers of (Annis et al. 2004) was considered. Each unique subclone over the full-length ITS region is represented, and thus, some unique subclones appear identical for only this small region. Branches receiving over $40 \%$ bootstrap support are shown in bold. Arrow indicates unsupported branch that separates all $B d$-Brazil haplotypes from those primarily found in Bd-GPL MLST genotypes. GPL, global panzootic lineage.

facilitated the hybridization of distinct $B d$ gene pools. Whether the $B d$-GPL genotypes were originally brought to Brazil on L. catesbeianus sometime after the 1930s when bullfrog farms were established or were already present cannot be discerned.
We argue that the data suggest $B d$-Brazil genotypes are endemic to Brazil rather than introduced from L. catesbeianus. Arguments in favour of Brazilian endemism of the $B d$-Brazil genotypes include, firstly, the occurrence of $B d$-Brazil genotypes on native Brazilian 


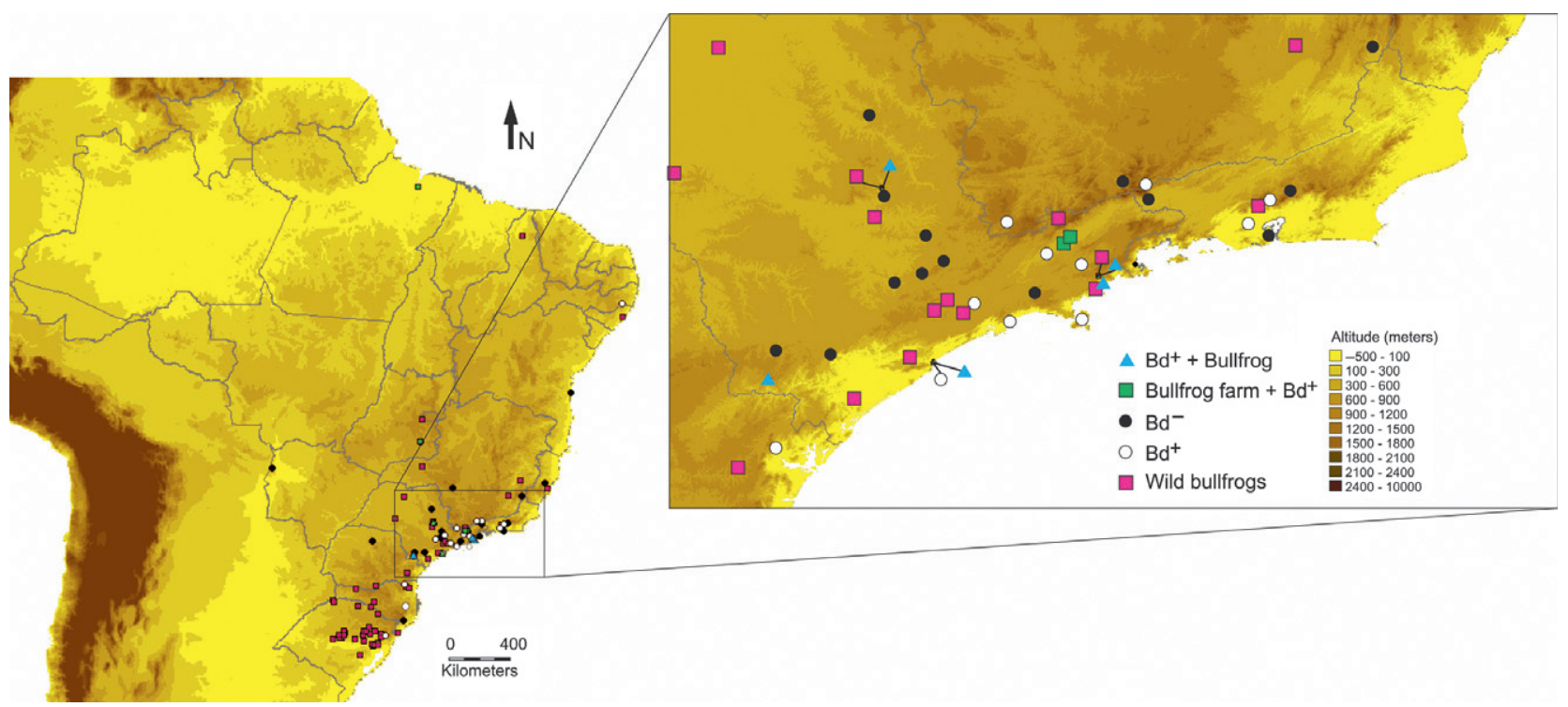

Fig. $7 \mathrm{Bd}$ and bullfrogs are widespread in the Atlantic Forest of Brazil. Map includes location of bullfrog (Lithobates catesbeianus) farms positive for the infection, alien wild populations of bullfrogs (not examined for the infection), native wild populations of anurans positive $(B d+)$ and negative $(B d-)$ for chytridiomycosis. Data from alien wild bullfrogs were extracted from (Giovanelli et al. 2008) and the remaining data are available in Data S2 (Supporting information).

amphibians and the general hyper-diversity of amphibians in this region (c. 300 endemic species in the Atlantic Forest alone), which predicts a high pathogen diversity (Hechinger \& Lafferty 2005). A second argument against a North American origin of the $B d$-Brazil genotypes is that we have sampled bullfrogs from eastern North America better than any other geographic region (Longcore et al. 2007; James et al. 2009) but have never recovered $B d$-Brazil genotypes except in a Michigan market on a L. catesbeianus, whose ultimate origin was probably a farm in Brazil. Thus, if $B d$-Brazil genotypes are endemic to Brazil, then they are on occasion aggressive enough to invade bullfrog farms and outcompete the more predominant $B d$-GPL strains. In that vein, it would be informative to know what $B d$ genotypes are involved in the few bullfrog farm collapses reported, such as the mass dieoff of 28,000 L. catesbeianus on a farm in Uruguay (Mazzoni et al. 2003). Lithobates catesbeianus has also invaded Europe and Central America (Lever 2003); the presence of $B d$ Brazil genotypes and the geographic origins of the L. catesbeianus source populations in these regions should also be investigated.

The earliest confirmed evidence (by diagnostic PCR) of chytridiomycosis was from a museum specimen of Xenopus fraseri from Cameroon 1933 (Soto-Azat et al. 2010). An even older potential infection of $B d$ has been suggested for a 1902 museum specimen of Andrias japonicas (Goka et al. 2009), although this finding has not been confirmed by PCR. Given the demonstration of multiple endemic lineages of $B d$, it is plausible that the earlier detected infections in Japan and Africa may be additional genotypes different from the currently globally circulating and deadly Bd-GPL. While archival specimens are useful for establishing a chronological profile of $B d$ spread, it cannot be assumed that historical infections represent the highly virulent panzootic genotype. Instead, $B d$ positive museum specimens collected prior to the global amphibian crisis (e.g. pre1960) (Houlahan et al. 2000) should be indicators of regions that might harbour novel endemic strains of $B d$ that were present before invasion by the virulent panzootic genotypes.

Given the recent development in tools to analyse archival samples (Cheng et al. 2011), these early infections could be assessed using PCR sequencing of the ITS rRNA region. However, based on our findings of multiple ITS haplotypes per strain (up to dozens), the use of the ITS region for inference of phylogeographic studies is problematic. In most organisms, the ITS of ribosomal RNA (rRNA) is typically homogenous within an individual owing to the phenomenon of concerted evolution (Ganley \& Kobayashi 2007). Goka et al. reported only a single ITS haplotype per $B d$ sample, with high levels of genetic diversity occurring in Japan relative to the few ITS sequences included from outside the country. In Japan, only three subclones were sequenced per sample, all of which were identical to the original haplotype. In the current study, we found from 7 to 22 distinct sequences per strain. Because each $B d$ strain has a large variety of ITS sequences, and no studies suggest that direct 
sequencing of ITS amplicons from swab DNA is representative of genotypic diversity of an infection, we suggest that the ITS region be used for phylogeographic studies only with great care. However, as a sensitive tool for detection of novel genotypes, the ITS region may ultimately be quite useful.

Why has the GPL been so successful at spreading across both endangered and healthy amphibian populations? Evidence supporting the $B d$-GPL as a hypervirulent multilocus genotype includes predominately clonal reproduction of the $B d-G P L$, suggesting the genotype possesses a particular combination of alleles that are being selected. It has been suggested that the $B d$-GPL may be a hybrid (James et al. 2009; Farrer et al. 2011), and meiosis could thus be blocked or recombination could lead to a potential loss of virulence through genetic reassortment, as observed in hybrid breakdown (Lynch \& Walsh 1998). Yet, genetic analyses of GPL isolates present clear evidence of both recombination and clonal reproduction; some loci display Mendelian ratios of genotypes while the majority of loci display a large excess of heterozygosity (Table 3). This chromosome-specific pattern of recombination has been hypothesized to be explained by variation in mitotic LOH across chromosomes (James et al. 2009). In contrast, sexual reproduction should act homogenously across the genome, and low rates of outcrossing are expected to eliminate excess heterozygosity (Balloux et al. 2003). In this study, we targeted many regions of the genome that were known to have undergone $\mathrm{LOH}$ in certain strains. Those marker loci now support the division of GPL into two groups, $B d-$ GPL-1 and $B d$-GPL-2. $B d$-GPL-1 has been primarily recovered from North America, but because of previous genotype surveys, it is likely that Bd-GPL-1 is also present in Europe (James et al. 2009). Because the overall observed heterozygosity of the two groups is the same (Table 4), we are unable to make a statement about the direction of progression of the panzootic, as has been possible in a study focused on $B d$ throughout the western part of North America and Central America (Velo-Anton et al. 2012).

Despite the absence of morphological and population genetic evidence of sex during the recent $B d$ panzootic, historical or very rare sexual reproduction may still occur, because in the complete absence of sex, genotypes are expected over time to become homozygous by $\mathrm{LOH}$. The isolation of a hybrid strain in this study is the strongest evidence to date for sexual reproduction in $B d$. An important corollary of this finding is that it suggests the production of a resting sporangial stage, because sex in all Chytridiomycota is associated with the production of a resting sporangium (Sparrow 1960). Because CLFT024/02 appears to be a biallelic hybrid between the $B d$-Brazil and $B d$-GPL lineages, the $B d$-GPL should be capable of undergoing meiosis.

The finding that $B d$ isolates range greatly in DNA content suggests that isolates vary in their ploidy. The twofold increase in DNA content in JEL423 relative to the $B d$-Brazil genotypes suggests that strains may differ from diploid to tetraploid. The derivation of a tetraploid nuclear state is unknown, but could suggest either a parasexual cycle in $B d$ that alternates between tetraploidy derived from mating of diploids with subsequent random chromosome loss to a diploid state, as has been described for Candida albicans (Bennett \& Johnson 2005), or the presence of a endomitotic process not involving any mixis at all (Kondrashov 1994). Evidence against parasexuality is that DNA content is not correlated with heterozygosity $(P>0.5)$ and in no case has a strain been found to have more than two alleles per locus. This is particularly relevant for the hybrid strain CLFT024/02 where tetra-allelic parasexual strains should be readily detected, yet only 1-2 alleles were observed per locus. Nonetheless, the strong correlation between spore size and DNA content could have implications for the evolution of virulence and transmission, for example, if larger spores carry more energy and swim for longer periods during dispersal between hosts.

In conclusion, our results increase the understanding of $B d$ diversity by detecting additional genotypic diversity and demonstrating a wide range of ploidy. In focusing on the North American bullfrog, we find that the species is not only widely dispersed from its native range, it is also infected with a large diversity of $B d$ genotypes, and its invasions are likely to have facilitated intercontinental gene flow. The growing globalization of the wildlife trade (Smith et al. 2009), increasing juxtaposition of human, livestock and wildlife populations (Jones et al. 2008), and our demonstration that $B d$ is capable of a sexual cycle, all predict that emergence owing to recombination between divergently adapted lineages could become a significant cause for future cross-species panzootics. These observations argue for additional global $B d$ surveillance and legislation to reduce the importation of live amphibians, particularly from and to areas of high amphibian endemicity (Schloegel et al. 2010a).

\section{Acknowledgements}

We gratefully acknowledge Patrícia Coelho Teixeira, Tara Chestnut, Danielle de Carla Dias, Antonio Mataresio Antonucci, Fernanda Menezes França, Adriana Sacioto Marcantonio, Jamie Bettaso, Donald Schultz, Myke Clarkson, Lucy Hou, Kam Yeong-Choy, Vance Vredenburg, Tina Cheng, Thaís Postali, Alessandra Nava, Nelson R. Silva, Isaias Santos, Ana Glaú- 
cia and S. Martins for their field assistance and sample collection. Lee Berger, Peter Murphy and Ché Weldon kindly provided strains used in these studies. Thanks also to Angela Picco, Ricardo Lombardi, Courtney Frye and Leah Murray for their laboratory assistance, and James P. Collins and Domingos S. Leite who provided laboratory space. FAPESP provided grants to LFT (08/50325-5). This work was funded by National Science Foundation IRCEB grants IBN \#9977063 and DEB02133851, The Eppley Foundation, The New York Community Trust, and EcoHealth Alliance and U. Michigan core funds.

\section{References}

Anderson EC, Thompson EA (2002) A model-based method for identifying species hybrids using multilocus genetic data. Genetics, 160, 1217-1229.

Annis SL, Dastoor FP, Ziel H, Daszak P, Longcore JE (2004) A DNA-based assay identifies Batrachochytrium dendrobatidis in amphibians. Journal of Wildlife Diseases, 40, 420-428.

Archie EA, Luikart G, Ezenwa VO (2008) Infecting epidemiology with genetics: a new frontier in disease ecology. Trends in Ecology and Evolution, 24, 21-30.

Balloux F, Lehmann L, de Meeus T (2003) The population genetics of clonal and partially clonal diploids. Genetics, 164, 1635-1644.

Bennett RJ, Johnson AD (2005) Mating in Candida albicans and the search for a sexual cycle. Annual Review of Microbiology, 59, 233-255.

Blaustein AR, Wake DB (1990) Declining amphibian populations: a global phenomenon? Trends in Ecology $\mathcal{E}$ Evolution, 7, 203-204.

Boyle DG, Hyatt AD, Daszak P et al. (2003) Cryo-archiving of Batrachochytrium dendrobatidis and other chytridiomycetes. Diseases of Aquatic Organisms, 56, 59-64.

Briggs CJ, Knapp RA, Vredenburg VT (2010) Enzootic and epizootic dynamics of the chytrid fungal pathogen of amphibians. Proceedings of the National Academy of Sciences of the United States of America, 107, 9695-9700.

Cheng TL, Rovito SM, Wake DB, Vredenburg VT (2011) Coincident mass extirpation of neotropical amphibians with the emergence of the infectious fungal pathogen Batrachochytrium dendrobatidis. Proceedings of the National Academy of Sciences of the United States of America, 108, 95029507.

Colwell RK (1997) EstimateS: statistical estimation of species richness and complementarity from samples. Available at: http://viceroy.eeb.uconn.edu/EstimateS\%02 (accessed on 26 November 2011).

Crawford AJ, Lips KR, Bermingham E (2010) Epidemic disease decimates amphibian abundance, species diversity, and evolutionary history in the highlands of central Panama. Proceedings of the National Academy of Sciences of the United States of America, 107, 13777-13782.

Daszak P, Cunningham AA, Hyatt AD (2000) Emerging infectious diseases of wildlife - threats to biodiversity and human health. Science, 287, 443-449.

Dray S, Dufour AB (2007) The ade4 package: implementing the duality diagram for ecologists. Journal of Statistical Software, 22, 1-20.
Farrer RA, Weinert LA, Bielby J et al. (2011) Multiple emergences of genetically diverse amphibian-infecting chytrids include a globalized hypervirulent recombinant lineage. Proceedings of the National Academy of Sciences of the United States of America, 108, 18732-18736.

Felsenstein J (1989) PHYLIP - phylogeny inference package (version 3.2). Cladistics, 5, 164-166.

Fisher MC, Walker SF, Garner TWJ (2009) The global emergence of Batrachochytrium dendrobatidis in space, time, and host. Annual Review of Microbiology, 63, 291-310.

Fisher MC, Henk DA, Briggs CJ et al. (2012) Emerging fungal threats to animal, plant and ecosystem health. Nature, 484, 186-194.

Flores Nava A (2005) Cultured aquatic species information programme. Rana catesbeiana. FAO Fisheries and Aquaculture Department, Rome.

Ganley ARD, Kobayashi T (2007) Highly efficient concerted evolution in the ribosomal DNA repeats: total rDNA repeat variation revealed by whole-genome shotgun sequence data. Genome Research, 17, 184-191.

Garner TWJ, Perkins MW, Govindarajulu P et al. (2006) The emerging amphibian pathogen Batrachochytrium dendrobatidis globally infects introduced populations of the North American bullfrog, Rana catesbeiana. Biology Letters, 2, 455-459.

Giovanelli JGR, Haddad CFB, Alexandrino J (2008) Predicting the potential distribution of the alien invasive American bullfrog (Lithobates catesbeianus) in Brazil. Biological Invasions, 10, 585-590.

Goka K, Yokoyama J, Une Y et al. (2009) Amphibian chytridiomycosis in Japan: distribution, haplotypes and possible route of entry into Japan. Molecular Ecology, 18, 4757-4774.

Guindon S, Gascuel O (2003) A simple, fast, and accurate algorithm to estimate large phylogenies by maximum likelihood. Systematic Biology, 52, 696-704.

Hechinger RF, Lafferty KD (2005) Host diversity begets parasite diversity: bird final hosts and trematodes in snail intermediate hosts. Proceedings of the Royal Society $B$ Biological Sciences, 272, 1059-1066.

Houlahan JE, Findlay CS, Schmidt BR, Meyer AH, Kuzmin SL (2000) Quantitative evidence for global amphibian population declines. Nature, 404, 752-755.

James TY, Litvintseva AP, Vilgalys R et al. (2009) Rapid expansion of an emerging fungal disease into declining and healthy amphibian populations. PLoS Pathogens, 5, e1000458.

Jombart $\mathrm{T}$ (2008) adegenet: a $\mathrm{R}$ package for the multivariate analysis of genetic markers. Bioinformatics, 24, 1403-1405.

Jones KE, Patel NG, Levy MA et al. (2008) Global trends in emerging infectious diseases. Nature, 451, 990-U994.

Kielgast J, Rodder D, Veith M, Lotters S (2010) Widespread occurrence of the amphibian chytrid fungus in Kenya. Animal Conservation, 13, 36-43.

Kondrashov AS (1994) The asexual ploidy cycle and the origin of sex. Nature, 370, 213-216.

Lever C (2003) Naturalized Amphibians and Reptiles of the World. Oxford University Press, New York.

Longcore JE (2000) Culture technics for amphibian chytrids: recognizing, isolating, and culturing Batrachochytrium dendrobatidis from amphibians, 52-54. 
Longcore JR, Longcore JE, Pessier AP, Halteman WA (2007) Chytridiomycosis widespread in anurans of northeastern United States. Journal of Wildlife Management, 71, 435-444.

Lynch M, Walsh B (1998) Genetics and Analysis of Quantitative Traits. Sinauer Associates Inc., Sunderland, MA.

Maddison D, Maddison W (2000) MacClade Version 4: Analysis of Phylogeny and Character Evolution. Version 4.08. Sinauer Associates, Sunderland, MA, USA.

Mazzoni R, Cunningham AA, Daszak P, Apolo A, Perdomo E, Speranza G. (2003) Emerging pathogen of wild amphibians in frogs (Rana catesbeiana) farmed for international trade. Emerging Infectious Diseases, 9, 995-998.

Morehouse EA, James TY, Ganley ARD et al. (2003) Multilocus sequence typing suggests the chytrid pathogen of amphibians is a recently emerged clone. Molecular Ecology, 12, 395-403.

Morens DM, Folkers GK, Fauci AS (2004) The challenge of emerging and re-emerging infectious diseases. Nature, 430, 242-249.

Morgan JAT, Vredenburg VT, Rachowicz LJ et al. (2007) Population genetics of the frog-killing fungus Batrachochytrium dendrobatidis. Proceedings of the National Academy of Sciences of the United States of America, 104, 13845-13850.

Mountain JL, Cavalli-Sforza LL (1997) Multilocus genotypes, a tree of individuals, and human evolutionary history. American Journal of Human Genetics, 61, 705-718.

Posada D (2008) jModelTest: phylogenetic model averaging. Molecular Biology and Evolution, 25, 1253-1256.

Pounds JA, Bustamante MR, Coloma LA et al. (2006) Widespread amphibian extinctions from epidemic disease driven by global warming. Nature, 439, 161-167.

Rachowicz LJ, Hero JM, Alford RA et al. (2005) The novel and endemic pathogen hypotheses: competing explanations for the origin of emerging infectious diseases of wildlife. Conservation Biology, 19, 1441-1448.

Raymond M, Rousset F (1995) GENEPOP (version 1.2): population genetics software for exact tests and ecumenicism. Journal of Heredity, 86, 248-249.

Retallick RWR, Miera V, Richards KL, Field KJ, Collins JP (2006) A non-lethal technique for detecting the chytrid fungus Batrachochytrium dendrobatidis on tadpoles. Diseases of Aquatic Organisms, 72, 77-85.

Rosenblum EB, Novembre J (2007) Ascertainment bias in spatially structured populations: a case study in the eastern fence lizard. Journal of Heredity, 98, 331-336.

Schloegel LM, Hero JM, Berger L, Speare R, McDonald K, Daszak P. (2006) The decline of the sharp-snouted day frog (Taudactylus acutirostris): the first documented case of extinction by infection in a free-ranging wildlife species? EcoHealth, 3, 35-40.

Schloegel LM, Picco AM, Kilpatrick AM, Davies AJ, Hyatt AD, Daszak P. (2009) Magnitude of the US trade in amphibians and presence of Batrachochytrium dendrobatidis and ranavirus infection in imported North American bullfrogs (Rana catesbeiana). Biological Conservation, 142, 1420-1426.

Schloegel LM, Daszak P, Cunningham AA, Speare R, Hill B (2010a) Two amphibian diseases, chytridiomycosis and ranaviral disease, are now globally notifiable to the World Organization for Animal Health (OIE): an assessment. Diseases of Aquatic Organisms, 92, 101-108.
Schloegel LM, Ferreira CM, James TY et al. (2010b) The North American Bullfrog (Rana catesbeiana) as a reservoir for the spread of Batrachochytrium dendrobatidis in Brazil. Animal Conservation, 13, 53-61.

Schloss PD, Westcott SL, Ryabin T et al. (2009) Introducing mothur: open-source, platform-independent, communitysupported software for describing and comparing microbial communities. Applied and Environmental Microbiology, 75, 7537-7541.

Skerratt LF, Berger L, Speare R et al. (2007) Spread of chytridiomycosis has caused the rapid global decline and extinction of frogs. EcoHealth, 4, 125-134.

Smith KF, Behrens M, Schloegel LM, Marano N, Burgiel S, Daszak P. (2009) Reducing the risks of the wildlife trade. Science, 324, 594-595.

Soto-Azat C, Clarke BT, Poynton JC, Cunningham AA (2010) Widespread historical presence of Batrachochytrium dendrobatidis in African pipid frogs. Diversity and Distributions, 16, 126-131.

Sparrow FK (1960) Aquatic Phycomycetes, 2nd edn. University of Michigan Press, Ann Arbor, MI.

Swofford DL (2002) PAUP*: Phylogenetic Analysis Using Parsimony (*and Other Methods). Version 4. Sinauer Associates, Sunderland, MA.

Velo-Anton G, Rodriguez D, Savage AE, Parra-Olea G, Lips KR, Zamudio KR. (2012) Amphibian-killing fungus loses genetic diversity as it spreads across the New World. Biological Conservation, 146, 213-218.

Walker DH, Barbour AG, Oliver JH et al. (1996) Emerging bacterial zoonotic and vector-borne diseases - ecological and epidemiological factors. JAMA - Journal of the American Medical Association, 275, 463-469.

Walker SF, Bosch J, James TY et al. (2008) Introduced pathogens threaten species recovery programs. Current Biology, 18, R853-R854.

Warnecke L, Turner JM, Bollinger TK et al. (2012) Inoculation of bats with European Geomyces destructans supports the novel pathogen hypothesis for the origin of white-nose syndrome. Proceedings of the National Academy of Sciences of the United States of America, 109, 6999-7003.

Weldon C, du Preez LH, Hyatt AD, Muller R, Speare R (2004) Origin of the amphibian chytrid fungus. Emerging Infectious Diseases, 10, 2100-2105.

White TJ, Bruns T, Lee S, Taylor JW (1990) Amplification and direct sequencing of fungal ribosomal RNA genes for phylogenetics. In: PCR Protocols: A Guide to Methods and Applications (eds Innis MA, Gelfand DH, Sninsky JJ and White TJ), pp. 315-322. Academic Press, Inc., New York.

This study represents a multi-institutional and multi-faceted approach to understanding the genetics of pathogen-mediated amphibian declines. L.M.S., A.J.D., and P.D. study wildlife disease and conservation. L.F.T. and C.A.V. study Atlantic Forest amphibians and isolated all cultures from native Brazilian species. J.E.L., S.E.G., M.L., S.Z., C.W., C.A.C., and T.Y.J. study fungal evolution and led the genotyping and phenotyping work. C.M.F. and M.H. provided expertise on the biology of ranaculture. 


\section{Data accessibility}

ITS rRNA sequences: GenBank accessions JQ582886-JQ582942.

The genotype matrix (Genepop format) and sequences have been uploaded as online supplemental material (Data S1, Supporting information). The $B d$ diagnostic data used for Fig. 7 are online supplemental material (Data S2, Supporting information). The alignment of ITS rRNA types (labelled with GenBank accession numbers) is posted as online supplemental material (Data S3, Supporting information). Estimates of spore size and DNA content are available as online supplemental material (Data S4, Supporting information).

\section{Supporting information}

Additional supporting information may be found in the online version of this article.

Fig. S1 Gene genealogies of individual MLST markers.
Fig. S2 Accumulation of phylogenetic diversity across groups of ITS rRNA sequences.

Table S1 New SNP genotyping primers and their location in the $B d$ genome (based on JEL423 assembly by the Broad Institute).

Data S1 BdMLST genotype data in Genepop format and representative allele sequences.

Data S2 $B d$ distribution in Brazil.

Data S3 Aligned ITS rRNA sequences in nexus format.

Data S4 Spore size and DNA content measurements.

Please note: Wiley-Blackwell is not responsible for the content or functionality of any supporting information supplied by the authors. Any queries (other than missing material) should be directed to the corresponding author for the article. 